\title{
Quality of care and utilisation of MCH and FP services at Kenyan health facilities
}

Lewis Ndhlovu

Follow this and additional works at: https://knowledgecommons.popcouncil.org/departments_sbsr-rh

Part of the Demography, Population, and Ecology Commons, International Public Health Commons, Maternal and Child Health Commons, and the Public Health Education and Promotion Commons How does access to this work benefit you? Let us know!

\section{Recommended Citation}

Ndhlovu, Lewis. 1999. "Quality of care and utilisation of MCH and FP services at Kenyan health facilities." New York: Population Council. 
February 1999

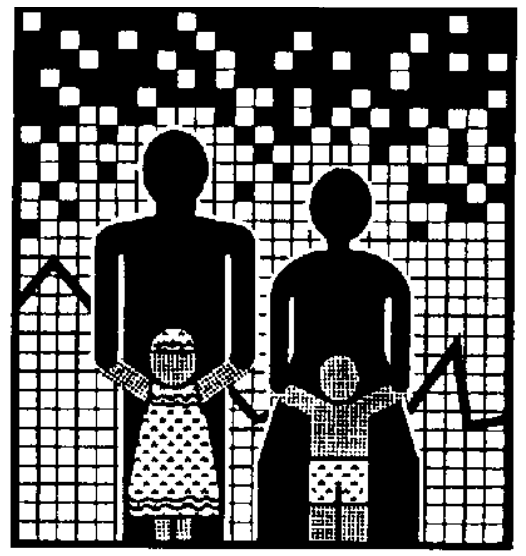

OPERATIONS

RESEARCH

TECHNICAL ASSISTANCE

AFRICA PROJECT II

THE POPULATION COUNCIL

\section{Quality of Care and Utilisation of $\mathrm{MCH}$ and FP Services at Kenyan Health Facilities}




\section{The Population Council}

The Population Council seeks to help improve the well-being and reproductive health of current and future generations around the world and to help achieve a humane, equitable, and sustainable balance between people and resources. The Council analyzes population issues and trends; conducts biomedical research to develop new contraceptives; works with public and private agencies to improve the quality and outreach of family planning and reproductive health services; helps governments to influence demographic behavior; communicates the results of research in the population field to appropriate audiences; and helps build research capacities in developing countries. The Council, a nonprofit, nongovernmental research organization established in 1952, has a multinational Board of Trustees; its New York headquarters supports a global network of regional and country offices.

\section{Africa OR/TA Project II}

The overall objective of the Africa OR/TA Project II is to broaden understanding of how to improve family planning services in Sub-Saharan Africa, and to apply operations research and technical assistance to improve services by:

- increasing access to a full range of family planning services and methods;

- developing service delivery strategies that are client-oriented and acceptable to various population groups;

- improving the operations of programs to make them more efficient and financially sustainable;

- improving the quality of services;

- strengthening the capabilities of family planning program managers to use operations research to diagnose and solve service delivery problems.

This project was supported by the Population Council's Operations Research and Technical Assistance Project II, Project No. 936-3030 funded by the United States Agency for International Development (USAID). 


\section{ACKNOWLEDGMENTS}

This study was undertaken with substantial technical assistance from a number of people and organisations. We acknowledge the dedicated work of the field supervisors and investigators who spent days at different hospitals, health centres and dispensaries in the country. The Ministry of Health of the Government of Kenya, the Christian Health Association of Kenya, the Family Planning Association of Kenya and Population Health Services facilitated visits to their health facilities.

Numerous colleagues at the Population Council have given valuable input to this report. In particular, I thank Dr Ian Askew of the Population Council and Professor John Cleland of the London School of Hygiene and Tropical Medicine.

Finally I gratefully acknowledge the support of USAID without whom this project would not have been possible. 



\section{TABLE OF CONTENTS}

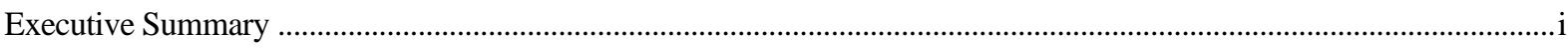

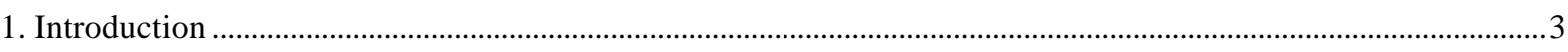

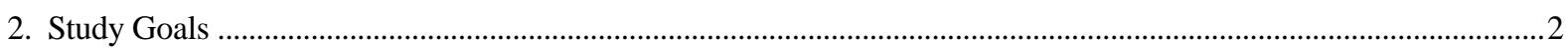

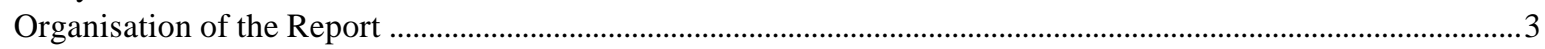

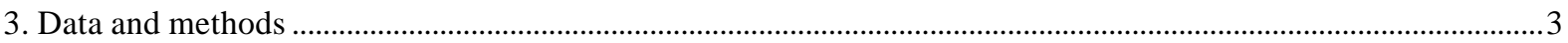

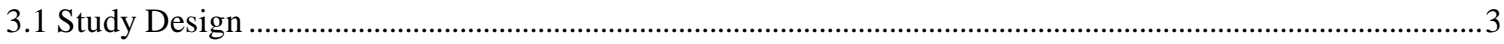

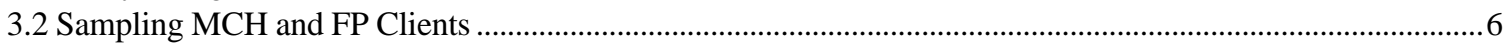

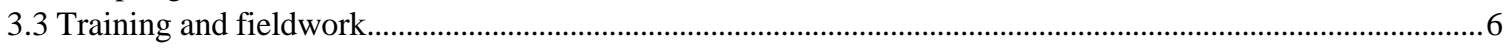

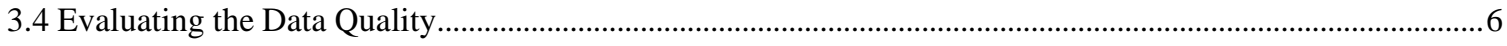

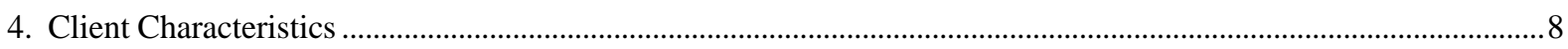

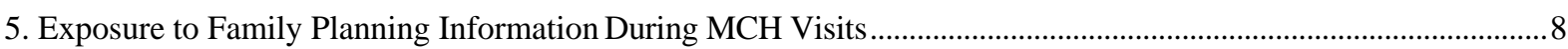

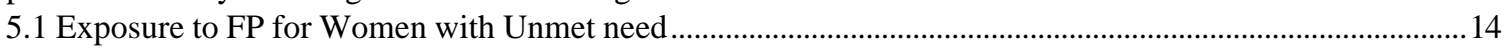

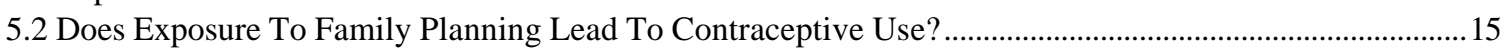

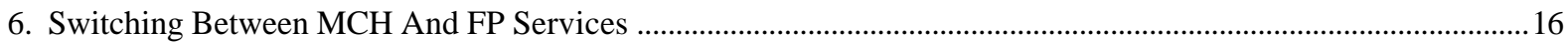

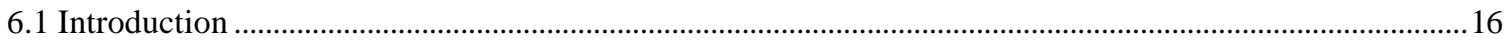

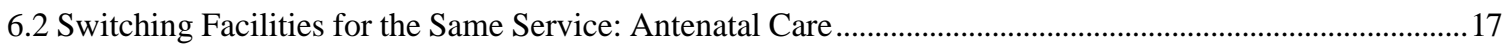

6.3 Switching Facilities for the Same Service: Child Welfare ………………….....................................................2

6.4 Switching Facilities between Services: ANC to Child Health.......................................................................22

6.5 Switching Facilities between Services: Child Health to FP ........................................................................2

6.6 Switching Facilities for the Same Service: Family Planning ...........................................................................2

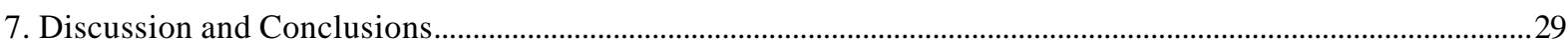

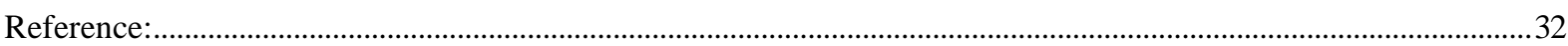




\section{Executive Summary}

The quality of services is playing an increasingly important role in many family planning programmes. Many family planning programmes have abandoned the emphasis of setting numerical goals as an indicator of programme achievement in favour of client-centred measurements. To attract new clients and improve continuity of use of contraceptives, providers endeavour to offer services that appeal to potential clients who are concerned about quality. The growth of management theories and new methods of quality assurance have made an impact on the health care industry and this has resulted in greater focus on client-centred services. Further, the call by the International Conference on Population and Development (1994) for more client-centred services has legitimised the importance of quality in reproductive health services.

In 1995, a national Situation Analysis Study of 254 health facilities was conducted in Kenya and the objective was to assess the status and quality of family planning services in the country. Based on this survey, an in-depth survey of a sub-sample of 28 health facilities was conducted the following year. From these facilities, 1834 women were interviewed about their experiences with services at facilities when they sought antenatal, child health and family planning services. For each woman, the experience was related to the last child.

The goal of the in-depth survey was to examine the links between quality of care in family planning services and contraceptive behaviour. A key focus of the study was directed at information and counselling as elements of service quality. Further, the subject of quality was explored in the context of how women switched facilities for the same and different services of antenatal care, child health and family planning.

Results from this study revealed that provision of information about reproductive health services was generally low and was mediated by providers' consideration of client's personal characteristics. Women's characteristics that were found to be important were age, marital status, number of children and education. Older women or those who were married were more likely to receive counselling from service providers. An increase in the number of children was generally associated with a higher likelihood of counselling. Women with secondary or higher education received more attention from providers than those less educated. In addition, the likelihood of counselling increased with the number of visits to a health facility and the type of facility visited. The chances of receiving counselling were highest among health centres compared to dispensaries or hospitals. Providers make sensible decisions of who to counsel, but these considerations can lead to restrictions of access to services. In particular, difficulties of access to contraceptive information faced by young adults or uneducated women is demonstrated.

Exposure of $\mathrm{MCH}$ clients to family planning information appeared to improve adoption of

contraceptive use. However, it was rather unexpected that there was no difference in the percentage of women exposed to family planning information among those with unmet need and those without. This suggests that service providers were not clear which clients to focus on.

Provider discussions about family planning on any single day were found to be relatively low. 
Approximately nine percent of antenatal women and nearly 10 percent of child welfare mothers were told about family planning services on the day of visit. Similarly, a small percentage of women reported that they had attended health talks. For women who attended health talks, about a fifth of them mentioned that the dominant themes at the talks were antenatal care, child health and family planning. Less than a tenth of women reported that the discussions covered information on STDs and AIDS. These results show that health talks as a mode of communicating reproductive health information to clients continues to be under-utilised and therefore need strengthening.

Women who switched facilities during their search for antenatal, child health and family planning services provided some insight into the role played by quality of services in their behaviour. The majority of clients seeking antenatal care, child welfare and family planning services tended to use the same facilities. Despite the long continuity of use of facilities for different services, providers did not take advantage of the frequent contacts that they had with clients. Several opportunities of educating women on reproductive health issues were missed by providers.

Women who switched facilities when they changed services provided insights into the importance of quality in reproductive health services. Apart from marital status, personal characteristics did not appear to play a significant role in women who changed health facilities when they switched services from child health to family planning services. However, it is interesting to note that women who had providers discuss family planning services with them during child health visits were more than one and half times more likely to continue seeking services from the same facility than those who were not counselled. This finding confirms the important role of integrating reproductive health information at different stages of women's reproductive lives.

The role of counselling is further demonstrated by the least switching associated with clients who chose their methods of contraception. Women who reported that they used contraceptives recommended by friends were more likely to switch facilities than those who chose their method or had depended upon a recommendation of providers. Least switching was observed among women who chose their contraceptive. This finding brings to the forefront the need for providers to counsel clients adequately in their choice of contraceptives. In addition, the sector of the facility where a woman sought family planning services influenced switching behaviour; women who attended NGO facilities were most likely to switch than those who visited Government or Nairobi City Council facilities. This switching was related to the cost of services at these facilities.

This study, as well as others, highlights the gap that exists in the provision of quality of services in reproductive health. Despite the call at the ICPD for client-centred services, there is evidence that a wide gap still remains in providing relevant information to clients. Programmes need to pay attention to this element of service provision and mechanisms that incorporate the client's perspective and integrate reproductive health information need to be investigated and implemented. 


\section{Introduction}

In the past decade, the study of quality of services in international family planning (FP) programmes in the developing world has intensified. A number of problems have emerged in studying the subject and these span from the simple definition of service quality under different environments to the more complex problems of relating service quality to clients' behavioural or demographic outcomes.

Despite the recognition of the importance of the topic, only a few empirical studies have been directed at addressing these issues. A major justification for the interest in service quality is its potential influence on reproductive behaviour. To date, evidence of this relationship is conflicting and inconclusive. Studies that seek to establish the relationship between accessibility of services, utilisation and quality of care have faced difficulties of separating the effect of different factors under study, and thus conclusions of relationships are weak and obscure (Chavoyan et al., 1984; Cochrane and Gibney, 1991; Wilkinson et al., 1993).

A few studies show a strong correlation between service factors with client's behavioural outcomes. The seminal analysis by Jain (1989) demonstrated that increasing availability of methods in a family planning program could result in higher contraceptive prevalence rates while also helping women to meet their reproductive goals. A prospective study of 7,800 women in Bangladesh showed that high standards of care from providers were associated with continuation with contraceptives and also greater likelihood of contraceptive adoption (Koenig et al., 1997). From East Java, Pariani (1991) showed that women who were given a method of their choice were more likely to continue longer with contraceptive use than those who did not. Improved client counselling given to clients has been reported to be associated with better continuation rates in the Gambia and Niger (Cotten et al, 1992).

For the past 10 years, the Population Council's Africa Operations Research Project has conducted a number of studies seeking to measure quality using the Bruce-Jain framework of quality of care (Bruce, 1990). These studies have revealed interesting observations about the functioning of health facilities. For instance, it has been observed that relatively few health facilities provide contraceptive services to the majority of new family planning clients. Mensch and others (1994) illustrate the point. From their study of services in Zimbabwe, Tanzania and Nigeria, they found that 25 percent of health facilities served 79 percent of new clients in Nigeria, 81 percent in Tanzania and 83 percent in Zimbabwe.

A number of possible explanations were proposed for these variations. Women's choice of health facilities could be a function of demand of services, that is, their desire to control fertility. Access factors such as cost of and distance to services may play an important role in the number of clients visiting health facilities. A third possible explanation could be that the varying quality of services at health facilities influences attendance at facilities. The quality of services and its potential influence on women's contraceptive behaviour was the subject of investigation for this study. 


\section{Study Goals}

The goal of this study is to examine the links between quality of care in family planning services and contraceptive behaviour.

Specifically, the objectives were to conduct a study in 28 health facilities in order to:

- Analyse the role of health facilities in influencing Maternal and Child Health (MCH) clients to use family planning services

- Identify and analyse facility factors that influence contraceptive and health facility switching and continuation behaviour among MCH and FP clients

0 Analyse the role of clients' individual characteristics in influencing the use of $\mathrm{MCH}$ and family planning services

\section{Outcome Measures}

0 Proportion of women exposed to family planning information during visits for antenatal and child health purposes

1 Proportion of women who switched health facilities when they sought antenatal, child health and family planning services

\section{Explanatory Variables}

- Individual characteristics - age, marital status, number of living children, educational level, desire for more children

0 Health facility characteristics - type and sector

The outcome variable, information given to clients about the services sought is an important element of service quality proposed by the Bruce-Jain and other frameworks of service quality. For this study, the objective will be to find out if exposure to family planning information as an element of quality had implications to contraceptive behaviour. The pattern of switching of health facilities will also be analysed and this behaviour is expected to reflect women's choice of services based on quality.

In this analysis, the type and sector of health facility visited by women are considered to be proxies for service quality. Three broad types of health facilities are considered; hospitals, health centres and dispensaries. Hospitals, which are generally located in urban areas and near to government headquarters, are expected to be better stocked with commodities and other supplies. More skilled staff are normally found at these types of facilities. The health centres are ranked second to the hospitals. Dispensaries, which are staffed by one or two professional nurses, are expected to offer the lowest quality of services. Women choose different types of facilities based on their perceptions of service quality. The broader definition of service quality that encompasses not only interpersonal relationships but also the infrastructure of the health facilities is based on the clients' more encompassing views of quality derived from a qualitative study conducted in 1995 (Ndhlovu, 1995).

$\mathrm{MCH}$ and family planning clients can seek services from facilities run by three sectors; the Government, private and Non Governmental Organisations (NGO). The main difference between sectors is that services from the private sector tend to be most expensive. The government and city council health facilities charge clients only a nominal fee. 


\section{Organization of the Report}

The next section presents the study design and methods of the study. This is followed by a discussion of exposure of clients to family planning information during visits for antenatal and child health services. Switching during $\mathrm{MCH}$ and family planning services constitutes the second half of the report. The overall discussion and conclusions are drawn and presented at the end.

\section{Data and methods}

\subsection{Study Design}

This study investigated the quality of care issues based on a sub-sample of 28 health facilities. One of the broad aims of the inquiry was to complement the cross-sectional snapshot findings revealed by the national situation analysis study conducted at 254 health facilities in 1995. In this survey, women were interviewed about their past use of health facilities for $\mathrm{MCH}$ and family planning services. The main objective was to find out the extent to which women switch from one facility to another in their search for antenatal, child welfare and family planning services and the role of service quality in this process. Such switching behaviour has never been studied in Kenya, despite its obvious relevance to the efficient running of an integrated service and its potential to illuminate possible defects and dissatisfactions with the services provided at specific facilities.

Analysis of patterns of family planning and MCH use of health facilities from the 1995 Situation Analysis Study showed that a small proportion of health facilities serves a relatively large proportion of all clients and that a large number of clinics serve few or no clients at all. These results were found

to be consistent with findings from earlier studies conducted in other African countries (Fisher, 1993). Figure A illustrates the point.

This research sought to explore this problem in the wider context of $\mathrm{MCH}$ and family planning service delivery since this is the context within which many African countries deliver family planning services 


\section{clients according to quartiles of health facilities (Kenya Situation Analysis,1995)}

At the same time, a wide variability among health facilities in the ratio of family planning visits to

Figure A: Percentage distribution of new and revisit family planning

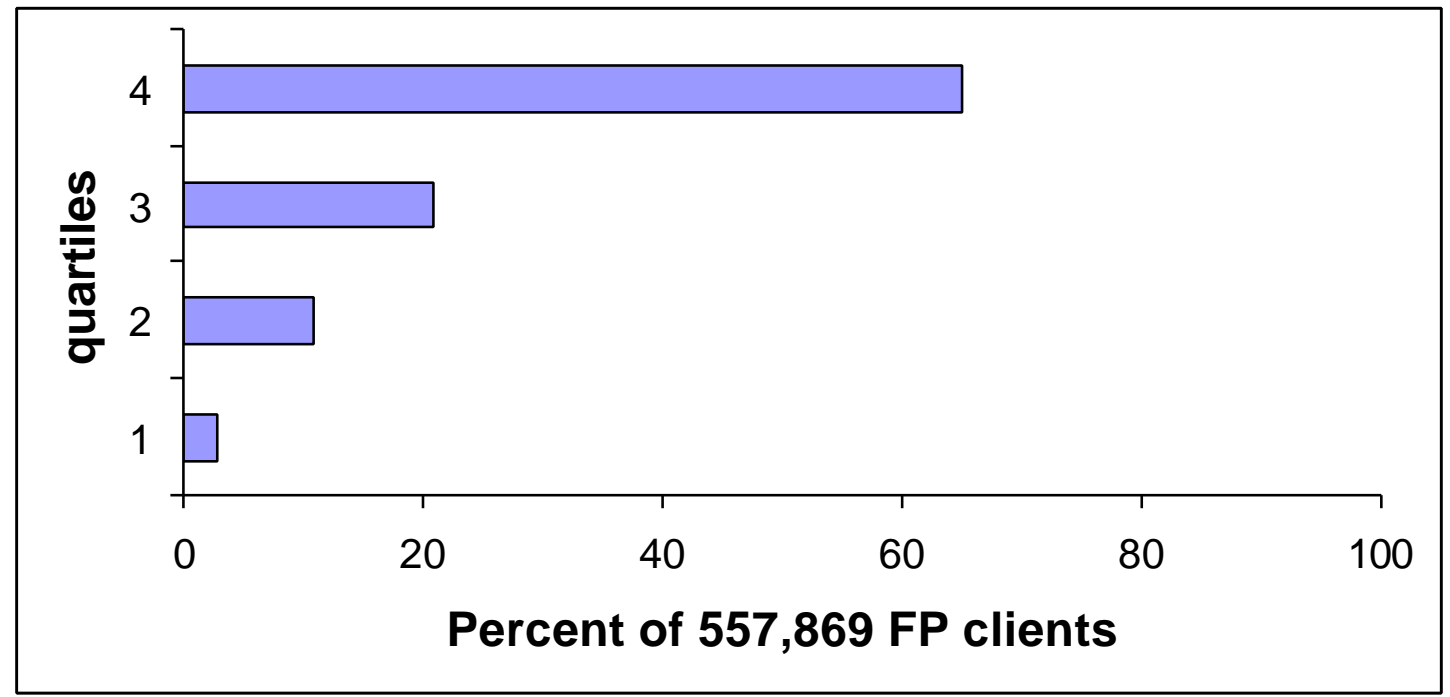

$\mathrm{MCH}$ visits, is indicated in Figure A. In some government health facilities there are nearly as many family planning visits as MCH visits while in other facilities, there were as few as one to two visits of FP clients per $100 \mathrm{MCH}$ visits. This variability is further illustrated in Table 1. Government health facilities were ranked in terms of the ratio of family planning to $\mathrm{MCH}$ visits and were grouped into quartiles. In the top quartile, the ratio of 72 family planning visits per $100 \mathrm{MCH}$ clients is observed. On the other hand, for the bottom quartile, the ratio is 9 per $100 \mathrm{MCH}$ visits.

\section{Table 1: Distribution of Total FP and MCH Client Visits According to Quartiles, Kenya Situation Analysis Study, 1995}

\begin{tabular}{|l|l|l|l|}
\hline QUARTILE & MCH VISITS & FP VISITS & RATIO FP/MCH \\
\hline First & 697,880 & 59,467 & .09 \\
\hline Second & 647,265 & 119,111 & .18 \\
\hline Third & 570,642 & 166,224 & .29 \\
\hline Fourth & 259,316 & 185,849 & .72 \\
\hline
\end{tabular}

It was hypothesized that the nature and quality of FP counselling and advise during $\mathrm{MCH}$ visits could be a major factor in determining the ratio of family planning acceptors and revisits to total $\mathrm{MCH}$ visits. Specifically, two main causal links between service quality and FP performance were hypothesised, the first one may be termed the conversion link: in high performing health facilities, 
there is more emphasis on exposing MCH clients to FP information, advice and counselling than in low performing health facilities. The second one may be termed the attraction link: some health facilities develop a reputation for provision of high quality FP services and thus attract women with a need for such services. The two links were not expected to be mutually exclusive and thus could be expected to operate simultaneously in some instances.

The case-control design was selected for studying the influence of service quality on clients. This design was based on a subsample of 28 health facilities obtained from the main Situation Analysis Study conducted in 1995. From 254 health facilities sampled during the national situation analysis study, MCH to FP ratios were calculated for each health facility. Cases were defined as health facilities with high ratios while controls had low ratios.

The pairs of facilities were matched as far as possible according to type (hospital, health centre, and dispensary) and geographical location to control for potentially confounding factors. This was viewed as important since different types of facilities tend to offer a different range and complexity of services. To control for demand of services, facilities were matched for location. This was important especially in urban areas where some facilities were located in low density suburbs compared to some that were situated next to large slums. For the rural areas, the demand of services could be affected by socio-cultural factors and thus rural facilities had to be within the same district. Table 2 shows the distribution of selected cases and controls according to provinces and types of facility.

Discussions were held with data collectors and knowledgeable people to match health facilities according to the criteria that had been set out. All the 14 pairs of health facilities that matched the criteria were selected for study. As seen earlier, the research used the case control design. The design paired 14 health facilities according to the relationship between the number of family planning and $\mathrm{MCH}$ clients. Ratios for each of the health facilities surveyed during the second phase were computed. The design matched health facilities with high ratios of family planning to MCH clients to those with low ratios within the same geographical area. The hypothesis was that the variation in the ratios could be attributable to the way activities at health facilities were influential in the uptake and continuation with contraceptive use.

\section{Table 2: Distribution of Selected Pairs of Cases and Controls According to Provinces and Types of Facilities}

\begin{tabular}{|l|l|l|l|}
\hline PROVINCE & HOSPITALS & HEALTH CENTRES & DISPENSARIES \\
\hline NAIROBI & & 4 & \\
\hline EASTERN & 2 & & 1 \\
\hline CENTRAL & 1 & & 1 \\
\hline NYANZA & & 1 & 1 \\
\hline WESTERN & & 1 & \\
\hline RIFT VALLEY & 1 & 1 & 3 \\
\hline TOTAL & 4 & 7 & \\
\hline
\end{tabular}




\subsection{Sampling MCH and FP Clients}

At each health facility, data collectors spent a week and interviewed all new and revisit family planning clients including the major categories of $\mathrm{MCH}$ clients visiting health facilities for antenatal and child welfare purposes. Women aged 15 to 44 years with at least one living child form the sample for MCH clients. It was important to sample women who had delivered at least one child since a major part of the investigation inquired about use history of the health facilities during antenatal and child welfare visits. In addition, reference to the last birth reduced recall errors among interviewees.

\subsection{Training and fieldwork}

Between 2nd and 10th October, 1996, 14 data collectors participated in the training held at Outspan hotel in Nyeri. The majority of the data collectors were drawn from the national Situation Analysis Study conducted in 1995. The training included reviewing each question for all the instruments, role-playing and a pre-test using the local health facilities. As soon as the training was completed, the teams were in the field for four weeks, spending a week per health facility.

The data collectors were divided into seven research teams, each consisting of two members with extensive experience in family planning service delivery and research and interviewing techniques. One team member was designated as a team leader with responsibility for arranging travel logistics, financial administration, ensuring adequate quality checks of the data collected, and general troubleshooting for the team.

\subsection{Evaluating the Data Quality}

The validity of data was evaluated using three sources. From the main survey of 1995, data on service statistics was collected about the total number of clients visiting health facilities for family planning and MCH purposes. Similar data were collected for the 28 health facilities visited in 1996. In addition, during this phase, data collectors stayed for a week at health facilities and, on a daily basis, recorded the actual number of $\mathrm{MCH}$ clients who sought services at the facilities. Ratios were calculated using data from the three data sources; the annual number of clients visiting for family planning and $\mathrm{MCH}$ services and the weeks totals. For the three data sets, the computed ratios were expected to have internal consistency and to be constant or vary within a narrow range.

The results showed wide variations of the 14 pairs of ratios for the three periods of data collection. Since there were no specific intervention programmes surrounding the 28 health facilities, this suggested that the data recorded by nurses was inaccurate. Additional information was obtained from the evaluation of the general status of the record system as judged by data collectors. Data collectors were required to judge whether the inventory and the record card systems were well completed, well ordered, partially ordered but usable or not usable at all. 
The wide variability of ratios supplemented with reports from data collectors cast doubt whether the original case control design could be used. Therefore, it was decided that the analysis will treat women as individual cases and not as part of the case control design. Therefore, this analysis is based on 1834 women interviewed at health facilities and had at least one child. On the day of interview, these women had visited facilities for different antenatal care (ANC), child health and family planning purposes. Despite this change, the link between service quality and reproductive behaviour could still be addressed by examining the integration of family planning information during $\mathrm{MCH}$ visits and clients' switching behaviour.

The ICPD agenda proposes the integration of a wide range of reproductive health services; $\mathrm{MCH}$, family planning and sexually transmitted infections. But before the integrating of sexually transmitted infections into $\mathrm{MCH}$ can be adopted, there is need to assess the status of current integration strategies implemented at health facilities when clients seek $\mathrm{MCH}$ and family planning services.

A demonstration of a successful strategy of educating $\mathrm{MCH}$ women about family planning has a great potential of application for disseminating other information needs to women. A simple calculation shows the potential use of this strategy. For example, in Kenya, the current total fertility rate, that is, the number of children a woman has during her reproductive life is currently estimated to be 4.7 (KDHS, 1998). Also, on average, a woman pays 13 visits to health facilities for antenatal care and child health purposes corresponding to one child. Based on these figures, the estimated lifetime number of visits to health facilities for $\mathrm{MCH}$ purposes is approximately 60. This large number of contacts between providers and clients offers a ready opportunity for service providers to provide information and education to women on a number of reproductive health issues.

The first part of the report will discuss how providers take advantage of their numerous contacts with clients in terms of information exchange. The second part of this report investigates how clients switch their use of health facilities as their reproductive health needs change from antenatal care to family planning services, a topic that has been little researched in Kenya or other African countries. Knowledge of clients' switching behaviour has great potential for application in learning about clients' requirements and the quality of services offered to them. Maternal, child health and family planning services are integrated in most African countries and yet there is a lack of knowledge about the extent to which these services meet the needs of communities. The objective of the health facilities is to provide continuous care to clients, and it is therefore important to know whether these goals are being achieved as women change their reproductive needs. The study of clients' switching should be viewed with keen interest by programme managers, since it may alert them to inadequate quality of services offered at their health facilities. Therefore, the analyses that follow are important for understanding the switching experience of women when they seek care for antenatal, child health and family planning services. 


\section{Client Characteristics}

Of the 1834 women who were interviewed, 29 percent had visited the health facility for antenatal care, 33 percent for family planning and 38 percent for child health services. The age range of these women was between 15 and 46 years with mean and median ages of 26 and 25 years. The majority of them (89 percent) were married. Though the mean number of years of schooling was two, sizeable proportions of them had attended primary (56 percent) and secondary school (36 percent). Only small percentages of women had never attended school (5 percent) at all or had received qualifications beyond secondary school level (3 percent). From women interviewed, we observe that visits to health facilities for antenatal and child welfare services were nearly universal. For most women, once they were pregnant, their first contact with antenatal care services was with Government health facilities, followed by those run by NCC health facilities and finally, NonGovernment Organisations (NGO). The same pattern is observed with respect to the percentage of women visiting health facilities for child health purposes. When data were analysed with respect to type of facility, it was found that the largest percentage of women first went to health centres for antenatal care or child welfare services. Hospitals and dispensaries respectively ranked second and third as the first choice of the type of facility.

For this sample, the number of visits to health facilities for antenatal care is relatively high. The median and mean number of visits to health facilities for antenatal care is approximately five and six respectively. These figures are consistent with the mean number of 4.7 visits reported by the 1994 Kenyan Demographic and Health Survey. The Kenyan government policy recommends that pregnant women should visit health facilities monthly for the first seven months, fortnightly during the 8th month, and then weekly until delivery. The data reported in this survey are positively biased towards women who use health facilities but, even among these women, visits fall far short of the recommended level.

\section{Exposure to Family Planning Information during $\mathrm{MCH}$ Visits}

This section of the report examines the degree of exposure of $\mathrm{MCH}$ clients to family planning information, the personal characteristics and facility factors that influence exposure. The results are derived from 1834 women who were asked to recall their experiences of antenatal and child welfare visits to health facilities. The experiences were related to the last child. For each of these services, they were asked if any health providers had talked to them about family planning, if they had seen any family planning posters or if they had personally discussed family planning services with other women while waiting for services. A discussion of the concept of unmet need, its relevance for client selection, followed by the influence of family planning information to contraceptive uptake concludes this section.

Surveys conducted in Kenya between 1989 and 1994 show general availability of information and education materials at health facilities with a marked improvement since 1989 (Ndhlovu et al., 1996). For instance, in 1989, 43 percent of health facilities were observed to have family planning 
posters and this figure increased to 74 percent in 1994. The percentage of facilities with pamphlets doubled to 74 percent between the two periods. Information, Education and Communication (IEC) materials displayed at facilities are intended to inform and educate women about different services. In addition, these materials are expected to trigger clients' curiosity about the content of the material so that they can inquire about services from providers or other women.

As expected, exposure to family planning information increases with the number of visits a woman pays to health facilities. Figure 1 demonstrates the cumulative effect of exposure for the three information exposure variables, provider counselling, IEC materials and women's discussions with each other. The graph shows that the level of exposure to print materials was higher than that for provider counselling and women's discussion. Provider counselling was lowest for each of the total number of visits. Though the general trend is upwards, there appears to be no further increase in exposure after the sixth visit.

Figure 1: Exposure to Family Planuing Information During Child Welfare Visits

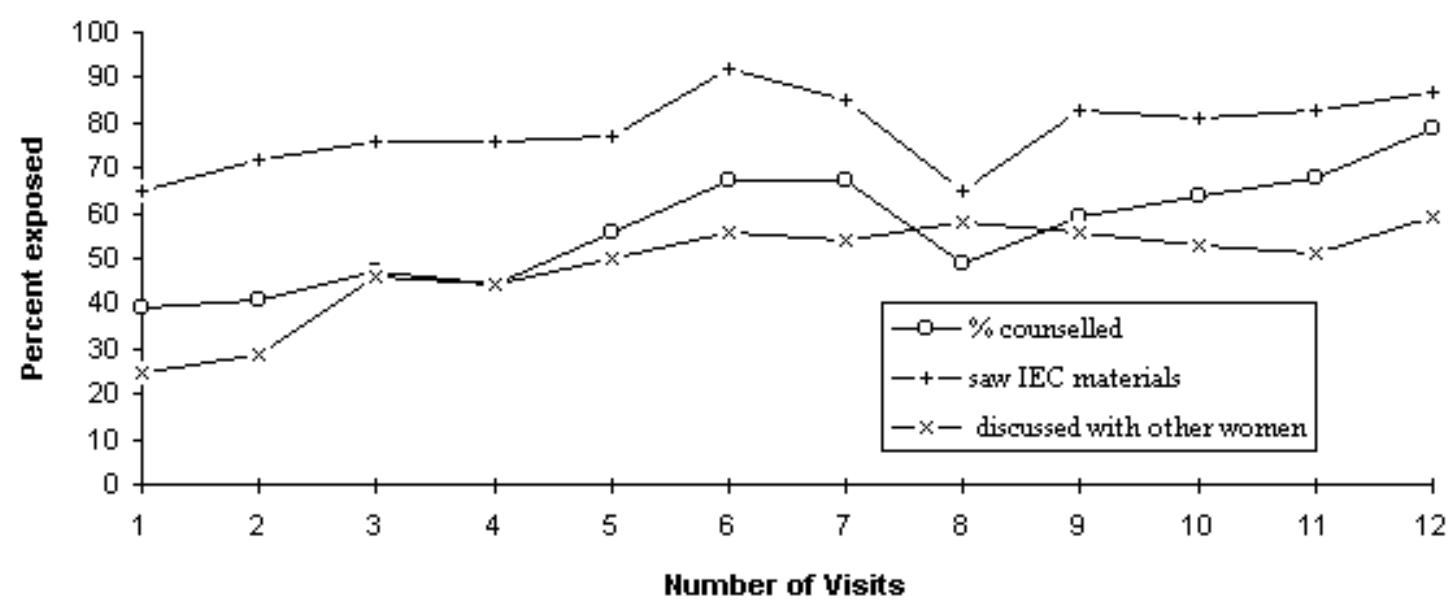

Of the three modes of family planning exposure (provider counselling, inter-client discussion and exposure to IEC materials), the highest percentage of women reported that they had seen IEC materials during $\mathrm{MCH}$ visits. During antenatal and child health visits, nearly 80 percent of women reported that they had seen IEC materials (Tables 3 and 4). The second most common form of exposure was through provider counselling, reported to be 40 and 44 percent for antenatal and child health visits, respectively. The mode of exposure that was least reported was women's discussion with each other.

Service providers are influenced by client's personal characteristics in their decisions of who to counsel for family planning services. Tables 3 and 4 show that certain types of clients are more likely to receive counselling than others during antenatal and child welfare visits. A larger percentage of older women were counselled than those in younger age groups. Married women were given preference to single women. With regard to future reproductive intentions, a higher percentage of women who said they did not want any more children were more likely to receive family planning counselling compared to those who did. The percentage of women who received counselling rises 
as the number of children increases. A higher percentage of educated women were counselled during child health visits compared to those with primary or no education though the relationship did not hold for antenatal visits. With regard to facility characteristics, the sector of the facility where women went influenced their chances of being counselled, with a higher proportion of women counselled at Government and NGO facilities. Results for antenatal and child welfare visits follow the same pattern though the figures are generally lower for antenatal visits. This means that providers put more effort into counselling women who visited for child health purposes than for antenatal care.

Family planning adoption may well be influenced by the spontaneous interchange of information among women waiting for MCH services at health facilities. Women were asked if they had ever talked with any other women about family planning services while waiting for services. The same personal and clinic factors were found to influence women's discussions with each other. Age, marital status, the number of children, a woman's desire for children, facility type and sector were significantly related to discussion. Education did not appear to be an influential variable for these discussions. A higher percentage of discussions were found among women who were older, married, with larger number of children and those who desired no more children. A higher percentage of women discussed family planning at health centres and Government facilities than at other types of facilities and sectors. 
Table 3: Percentage of women exposed to family planning during child health visits to health facilities with respect to the last child by selected characteristics

\begin{tabular}{|c|c|c|c|c|}
\hline Personal Characteristics & $\begin{array}{l}\text { Number of } \\
\text { Women } \\
\end{array}$ & $\begin{array}{l}\% \text { given FP } \\
\text { counselling }\end{array}$ & $\begin{array}{l}\text { \% Who Saw FP } \\
\text { IEC materials }\end{array}$ & $\begin{array}{l}\text { \% Discussed FP } \\
\text { with other women }\end{array}$ \\
\hline All & 1834 & 55.1 & 77.8 & 46.5 \\
\hline $\begin{array}{l}\text { Age } \\
15-19 \\
20-29 \\
30-46 \\
\end{array}$ & $\begin{array}{l}178 \\
1211 \\
407\end{array}$ & $\begin{array}{l}38.8 \\
54.6 \\
63.3 \\
\end{array}$ & $\begin{array}{l}67.2 \\
78.8 \\
79.7\end{array}$ & $\begin{array}{l}30.2 \\
45.5 \\
56.0\end{array}$ \\
\hline p-value & & 0.000 & 0.000 & 0.000 \\
\hline $\begin{array}{l}\text { Marital Status } \\
\text { Married } \\
\text { Single } \\
\end{array}$ & $\begin{array}{l}1615 \\
197 \\
\end{array}$ & $\begin{array}{l}56.9 \\
40.1 \\
\end{array}$ & $\begin{array}{l}79.4 \\
64.8 \\
\end{array}$ & $\begin{array}{l}47.6 \\
36.5 \\
\end{array}$ \\
\hline p-value & & 0.000 & 0.000 & 0.003 \\
\hline No. of Living Children & & & & \\
\hline $\begin{array}{l}1 \\
2 \\
3 \\
4+\end{array}$ & $\begin{array}{l}710 \\
452 \\
251 \\
394 \\
\end{array}$ & $\begin{array}{l}49.0 \\
59.1 \\
58.6 \\
59.5 \\
\end{array}$ & $\begin{array}{l}77.3 \\
79.9 \\
78.9 \\
76.1 \\
\end{array}$ & $\begin{array}{l}38.8 \\
48.9 \\
52.8 \\
53.8\end{array}$ \\
\hline p-value & & 0.000 & 0.563 & 0.000 \\
\hline $\begin{array}{l}\text { Highest Education Level } \\
\text { None or Primary } \\
\text { Secondary }+\end{array}$ & $\begin{array}{l}1108 \\
659\end{array}$ & $\begin{array}{l}52.6 \\
593\end{array}$ & $\begin{array}{l}74.9 \\
82.5\end{array}$ & $\begin{array}{l}46.2 \\
46.9\end{array}$ \\
\hline$p$-value & & 0.006 & 0.000 & 0.782 \\
\hline $\begin{array}{l}\text { Desire for more children } \\
\text { Yes } \\
\text { No } \\
\text { Undecided }\end{array}$ & $\begin{array}{l}994 \\
676 \\
143\end{array}$ & $\begin{array}{l}51.5 \\
59.9 \\
56.6\end{array}$ & $\begin{array}{l}77.3 \\
78.4 \\
79.4\end{array}$ & $\begin{array}{l}42.7 \\
52.5 \\
43.4\end{array}$ \\
\hline p-value & & 0.003 & 0.784 & 0.000 \\
\hline $\begin{array}{l}\text { Number of Visits } \\
1-2 \\
3-5 \\
6-9 \\
10 \text { and above }\end{array}$ & $\begin{array}{l}454 \\
436 \\
469 \\
401 \\
\end{array}$ & $\begin{array}{l}40.2 \\
48.7 \\
60.1 \\
69.2 \\
\end{array}$ & $\begin{array}{l}68.7 \\
76.3 \\
81.7 \\
83.0 \\
\end{array}$ & $\begin{array}{l}27.2 \\
46.7 \\
56.4 \\
54.5 \\
\end{array}$ \\
\hline p-value & & 0.000 & 0.000 & 0.000 \\
\hline $\begin{array}{l}\text { Type of Facility } \\
\text { Dispensary } \\
\text { Hospital } \\
\text { Health Centre }\end{array}$ & $\begin{array}{l}274 \\
929 \\
585\end{array}$ & $\begin{array}{l}51.1 \\
56.8 \\
55.2\end{array}$ & $\begin{array}{l}72.2 \\
81.9 \\
74.5\end{array}$ & $\begin{array}{l}40.5 \\
50.0 \\
43.9\end{array}$ \\
\hline$p$-value & & 0.242 & 0.000 & 0.06 \\
\hline $\begin{array}{l}\text { Sector of Facility Visited } \\
\text { Government } \\
\text { NGO } \\
\text { NCC } \\
\end{array}$ & $\begin{array}{l}843 \\
350 \\
592 \\
\end{array}$ & $\begin{array}{l}51.1 \\
54.9 \\
62.0\end{array}$ & $\begin{array}{l}69.7 \\
78.2 \\
89.9\end{array}$ & $\begin{array}{l}51.1 \\
39.3 \\
44.6 \\
\end{array}$ \\
\hline p-value & & 0.000 & 0.000 & 0.000 \\
\hline
\end{tabular}




\section{Table 4: Percentage of women exposed to family planning during antenatal visits to health facilities with respect to the last child by selected characteristics}

\begin{tabular}{|c|c|c|c|c|}
\hline Personal Characteristics & $\begin{array}{l}\text { Number of } \\
\text { Women }\end{array}$ & $\begin{array}{l}\text { \% given FP } \\
\text { counselling }\end{array}$ & $\begin{array}{l}\% \text { Who Saw FP } \\
\text { IEC materials }\end{array}$ & $\begin{array}{l}\text { \% Discussed FP with } \\
\text { other women }\end{array}$ \\
\hline Overall & 1834 & 49.6 & 79.3 & 47.5 \\
\hline $\begin{array}{l}\text { Age } \\
15-19 \\
20-29 \\
30-46 \\
\end{array}$ & $\begin{array}{l}171 \\
1191 \\
400 \\
\end{array}$ & $\begin{array}{l}30.4 \\
48.2 \\
60.5\end{array}$ & $\begin{array}{l}69.2 \\
80.2 \\
81.1\end{array}$ & $\begin{array}{l}33.1 \\
46.3 \\
56.0\end{array}$ \\
\hline $\mathrm{p}$-value & & 0.000 & 0.002 & 0.000 \\
\hline $\begin{array}{l}\text { Marital Status } \\
\text { Married } \\
\text { Single } \\
\end{array}$ & $\begin{array}{l}1591 \\
187\end{array}$ & $\begin{array}{l}50.6 \\
39.6 \\
\end{array}$ & $\begin{array}{l}80.1 \\
72.5\end{array}$ & $\begin{array}{l}48.8 \\
35.6 \\
\end{array}$ \\
\hline$p$-value & & 0.004 & 0.015 & 0.001 \\
\hline $\begin{array}{l}\text { No. of Living Children } \\
1 \\
2 \\
3 \\
4+\end{array}$ & $\begin{array}{l}695 \\
440 \\
248 \\
390\end{array}$ & $\begin{array}{l}41.1 \\
49.6 \\
52.2 \\
61.3\end{array}$ & $\begin{array}{l}77.7 \\
80.4 \\
79.8 \\
81.0\end{array}$ & $\begin{array}{l}38.2 \\
50.1 \\
54.2 \\
57.2\end{array}$ \\
\hline p-value & & 0.000 & 0.557 & 0.000 \\
\hline $\begin{array}{l}\text { Highest Education Level } \\
\text { None or Primary } \\
\text { Secondary }+\end{array}$ & $\begin{array}{l}1082 \\
651 \\
\end{array}$ & $\begin{array}{l}49.5 \\
49.2 \\
\end{array}$ & $\begin{array}{l}76.8 \\
83.4\end{array}$ & $\begin{array}{l}48.6 \\
46.1 \\
\end{array}$ \\
\hline $\mathrm{p}$-value & & 0.877 & 0.001 & 0.315 \\
\hline $\begin{array}{l}\text { Woman desires } \\
\text { Yes } \\
\text { No } \\
\text { Undecided }\end{array}$ & $\begin{array}{l}975 \\
664 \\
140\end{array}$ & $\begin{array}{l}44.4 \\
57.5 \\
45.7\end{array}$ & $\begin{array}{l}78.7 \\
80.7 \\
77.4\end{array}$ & $\begin{array}{l}44.1 \\
53.4 \\
43.5\end{array}$ \\
\hline p-value & & 0.000 & 0.517 & 0.001 \\
\hline $\begin{array}{l}\text { Number of Visits } \\
1-2 \\
3-5 \\
6-9 \\
10 \text { and above }\end{array}$ & $\begin{array}{l}159 \\
882 \\
511 \\
177\end{array}$ & $\begin{array}{l}34.0 \\
48.5 \\
50.6 \\
59.3\end{array}$ & $\begin{array}{l}67.5 \\
80.4 \\
78.0 \\
82.7\end{array}$ & $\begin{array}{l}32.9 \\
48.5 \\
51.9 \\
44.1\end{array}$ \\
\hline p-value & & 0.000 & 0.002 & 0.000 \\
\hline $\begin{array}{l}\text { Type of Facility } \\
\text { Dispensary } \\
\text { Hospital } \\
\text { Health Centre }\end{array}$ & $\begin{array}{l}265 \\
843 \\
672 \\
\end{array}$ & $\begin{array}{l}44.2 \\
49.8 \\
51.0\end{array}$ & $\begin{array}{l}72.2 \\
82.8 \\
77.6\end{array}$ & $\begin{array}{l}38.8 \\
50.5 \\
48.3\end{array}$ \\
\hline $\mathrm{p}$-value & & 0.157 & 0.000 & 0.000 \\
\hline $\begin{array}{l}\text { Sector of Facility Visited } \\
\text { Government } \\
\text { NGO } \\
\text { NCC }\end{array}$ & $\begin{array}{l}859 \\
392 \\
523\end{array}$ & $\begin{array}{l}47.7 \\
49.2 \\
52.4\end{array}$ & $\begin{array}{l}75.2 \\
78.4 \\
87.1\end{array}$ & $\begin{array}{l}53.3 \\
39.4 \\
43.9\end{array}$ \\
\hline p-value & & 0.243 & 0.000 & 0.000 \\
\hline
\end{tabular}


The bi-variate analysis presented in Tables 3 and 4 was taken further by the application of advanced statistical techniques to assess adjusted or net effects of different explanatory variables. The analysis of women's experiences during antenatal visits shows very similar results to those observed for child health visits and therefore, only results based on reports of women's visits for child health services are presented. The dependent variables of interest are 1) exposure to provider counselling 2) whether clients saw IEC materials at health facilities and 3) whether women discussed family planning with each other. Personal characteristics discussed above are considered as explanatory variables, together with the type and sector of facility

When each of the variables are considered individually, all except the type of facility were found to have a statistically significant association with provider counselling. In comparison to the reference group (14-19 years), exposure among women aged 20 -29 years and 30-34 years increases gradually; the older the woman, the more likely she was to receive counselling from a service provider. Similarly, the likelihood of exposure increases with number of children. Single women were nearly half as likely to be counselled than married women. More educated women had an odds of 1.31 of being counselled by a service provider. Providers also paid more attention to women who did not want to have more children and those who were undecided about plans for future child bearing than those who wanted more children.

Discussions about family planning amongst women attending health facilities for child health purposes were found to be highly influenced by nearly all individual and facility characteristics. When each of the characteristics is considered individually, all the characteristics except education showed that they were significantly associated with discussions. The direction of the relationships between personal characteristics and exposure to discussions is the same as discussed earlier with respect to provider counselling. When the variables are adjusted for each other, age and marital status are the only two characteristics to retain a net effect.

The link between type and sector of facility and inter-client discussion is unexpected. NCC and NGO facilities which have been positively associated with other exposure variables (provider counselling and seeing IEC materials) appear to be the least conducive environments for women to discuss family planning. The probable explanation is geographical in nature. NCC facilities are located in a metropolitan setting where people are less likely to know each other and thus less likely to discuss with each other personal matters as family planning. NGO facilities are generally located in urban and semi-urban locations where the same type of urban behaviour would be expected. Clients from NGO facilities were also observed to display a high degree of switching that would make it difficult for them to form long bonding relationships with other clients. Conversely, at government facilities, which are likely to be rural, women are more likely to know each other and to discuss reproductive health issues more easily than in towns or cities.

Exposure to family planning through provider counselling and women's discussions were closely associated with the sector and type of facilities where women sought services. For instance, women who sought services from the Nairobi City Council (NCC) health facilities had a higher chance of being counselled than those attending government and NGO facilities. At the same time, the type of facilities visited did not appear to influence the likelihood of counselling. On the other hand, the type of facility where a woman sought child health services was related to the likelihood of discussing 
family planning services with other women services. Women attending hospitals had a greater chance of striking a conversation with others than at health centres and dispensaries. The effect remained significant even after adjustment for other variables. The explanation for this behaviour is not obvious.

\subsection{Exposure to FP for Women with Unmet need}

In addition to reducing population growth rates, a major goal of family planning programmes in Africa, is to help couples to achieve their reproductive intentions. To assist clients to achieve these goals, service providers have to be in a position to identify clients' needs.

The concept of unmet need appears particularly relevant for service providers who are in a position to inform and educate $\mathrm{MCH}$ clients about contraceptive use and other reproductive health issues. Studies have shown that women who know of contraceptive methods and are aware of sources of supplies are less likely to have unmet need (Westoff and Bankole, 1994). Since service providers come into contact with a large number of $\mathrm{MCH}$ and family planning clients, the concept appears useful for administering their family planning programmes.

This study shows that providers miss a great opportunity for counseling clients who visit health facilities and have unmet need for family planning services. Although 46 percent of women stated that they wanted to have more children, about 90 percent of them wanted to wait for at least a year before the next birth. Just over a third of women who were not pregnant were using contraceptives. Women defined as having unmet need, that is, those who were not using contraceptives and did not want to have children immediately, constituted 34 percent of this group of women. These figures depict an environment of unmet need with a great potential for service providers to exploit.

In general, a small percentage of clients were counselled on family planning, irrespective of what group they belonged to (Table 5). We also note from the same table that providers did not consider the unmet need status of their clients when they selected them for family planning counselling. Women were equally likely to be counselled regardless of their pregnancy, contraceptive use status and future reproductive intentions. One would expect that providers would put more emphasis on women who were not using contraceptives in the hope that they would adopt contraception. There is confusion about how to deal with women who were pregnant. While at the time of survey, these women were not a risk of conception it is possible that some of the pregnancies carried could have been a result of unmet need for contraceptives. 


\section{Table 5: Women with Different Levels of Unmet Need and Exposure to FP Information}

\begin{tabular}{|c|c|}
\hline Need Status & Percentage Counselled on FP \\
\hline Already Using Contraceptives & 7.7 \\
Yes (n=233) & 10.0 \\
No (418) & 0.326 \\
\hline P value & 9.3 \\
\hline Currently Pregnant & 9.8 \\
Yes (n=430) & 0.786 \\
No (n=746) & \\
\hline P Value & 10.7 \\
\hline Wanted Child Soon & 8.7 \\
No (n=647) & 0.270 \\
Yes (n=443) immediate & 6.7 \\
\hline P Value & 10.1 \\
\hline With Unmet Need & 0.146 \\
Yes (n=176) & \\
No (n=1011) & \\
\hline P Value & \\
\hline
\end{tabular}

\subsection{Does Exposure To Family Planning Lead to Contraceptive Use?}

A major rationale for promoting IEC activities at health facilities is that it is presumed to influence women's reproductive behaviour so that they can initiate contraceptive use or improve continuation with services for those already using.

The relationship between contraceptive initiation and exposure to family planning information was investigated by linking exposure to family planning during antenatal care and subsequent uptake of contraceptive use. Women who had prior experience with contraceptive use were excluded since they already knew where to get services. In this case, from 1832 women who were interviewed, 27 percent already had previous experience with contraceptive use. Uptake of contraceptive use in this group could not be justifiably linked to the influence of information during antenatal visits. On the other hand, antenatal care at facilities preceded contraceptive initiation for women had no prior experience with family planning use. For child welfare clients, it would be difficult to distinguish the order of events between initiation of contraception and visits to facilities for childcare and therefore these clients are not included.

Table 6 shows the relationship between contraceptive use and counselling during antenatal care. Based on bivariate frequency distributions and unadjusted odds ratios, results show a strong statistical association between contraceptive uptake and exposure to family planning. Women who stated that they had been counselled by providers, or those who had seen IEC materials or discussed family planning with other women were nearly twice as likely to initiate contraception than their counterparts. These results strongly link exposure to family planning information with contraceptive initiation and provide evidence supporting IEC programme strategies. 


\section{Table 6: Contraceptive Use and exposure to provider counselling, IEC materials and discussions with other women}

\begin{tabular}{|c|l|l|l|}
\hline Exposure to FP information & $\begin{array}{l}\text { \% who used contraceptive } \\
\text { after antenatal visits }\end{array}$ & $\begin{array}{l}\text { Unadjusted odds ratios and } \\
\mathbf{9 5} \% \text { confidence intervals }\end{array}$ & Number of cases \\
\hline $\begin{array}{c}\text { Provider Counselling } \\
\text { No }\end{array}$ & 37.6 & 1.00 & \\
Yes & 46.0 & $2.13^{* *}(1.61-2.83)$ & 682 \\
\hline Saw IEC material & & & 602 \\
No & 34.6 & 1.00 & \\
Yes & 49.6 & $1.94 * *(1.38-2.76)$ & 292 \\
\hline Discussed with other women & & 1.00 & 978 \\
No & 39.3 & $2.04 * *(1.44-2.71)$ & 722 \\
Yes & 44.4 & \multicolumn{2}{|l}{} \\
\hline
\end{tabular}

Note to table: Confidence intervals are shown in brackets; ${ }^{* *}$ Significant at 0.01 .

\section{Switching Between MCH and FP Services}

\subsection{Introduction}

Health practitioners encourage the use of health facilities during pregnancy and early childhood to foster better health for mothers and their children. While demographic surveys show extensive use of facilities for antenatal and child welfare purposes, program managers do not know how consistently mothers use the same facility for the same type of service and the degree of switching to another facility when needs change. This section investigates if women who attended health facilities for pregnancy monitoring also used the same facilities for monitoring their children's health and subsequently as sources for family planning services. These issues are addressed by analysing women's visits to health facilities during pregnancy with the last child and subsequent visits for child care and family planning services.

Limited research has been done in Kenya or other African countries to investigate how clients use health facilities, as their reproductive health needs change from antenatal care to family planning services. Knowledge of clients' switching behaviour has great potential for application in learning about clients' requirements and the quality of services offered to them. Maternal, child health and family planning services are integrated in most African countries and yet there is a lack of knowledge about the extent to which these services meet the needs of communities. The objective of the health facilities is to provide continuous care to clients, and it is therefore important to know whether these goals are being achieved as women change their reproductive needs. The study of clients' switching should be viewed with keen interest by programme managers since it may alert them to inadequate quality of services offered at their health facilities.

The discussion that follows explores the possible influence of clients' personal (age, marital status, number of living children, educational level) and facility characteristics on their switching behaviour. The three types of health facilities, hospitals, health centres and dispensaries are expected to offer 
different choices to women at various stages of their reproductive lives, reflecting variations in available equipment, trained staff and personal interaction with clients. Similarly, different sectors (public, Nairobi City Council and NGO) have different management styles and devote different levels of resources to their facilities and this can present clients with different service quality options. An earlier study report of clients' views of service quality based on focus group discussions and indepth interviews showed that clients made decisions to change facilities based on the cost of services, the distance to facilities and perceptions of the quality of service offered. The cost and quality of services were associated with whether a facility visited belonged to NGO, the private or public sectors.

The organisation of this section reflects the natural sequence of the reproductive stages of women: from pregnancy to child care and contraceptive adoption. Therefore, the first part of the discussion will examine the switching behaviour of women when they seek care during pregnancy and after delivery. This is followed by an analysis of women switching facilities for child health purposes. Finally, the section concludes with an exploration of switching of facilities when women sought family planning services.

Exit interviews with women attending the sub-sample of 28 health facilities who had at least a child provided information about use of facilities. These women were asked a series of questions to find out the names of health facilities visited for antenatal, child health and family planning services in the period before and after their last live birth. For example, for antenatal care, the woman was asked;

"What is the name of the first health facility that you visited for antenatal services?"

Once the name was given, the respondent and interviewer established the sector and type of the facility. Then the above question was followed by

“ Did you use this health facility throughout your pregnancy or did you switch to another health facility for antenatal services?"

Women who had switched facilities were asked for the name of the new facility switched to and reasons for switching. Again, wherever possible, the types and sectors of health facilities were established. This helped to determine whether a woman visited the same type or sector of facility. A similar sequence of questions was asked with respect to visits for child care and family planning services.

\subsection{Switching Facilities for the Same Service: Antenatal Care}

Switching from one facility to another for antenatal services was not common among women who were interviewed though a small group of 159 (9 percent) did so. Investigation of this group shows that personal traits, the type and sector of the facilities first visited may help us to understand some of the switching behaviour reported by clients.

Switching behaviour for antenatal services was related to two personal characteristics of women, educational level, the number of children as well as the type and sector of facility (Table 7). A higher percentage (12 percent) of women with secondary education was observed to switch facilities than 
those with primary or no education ( 7 percent). An inverse relationship is indicated between the percentage of women who switched facilities with the number of children a woman had; the range was 5 percent among women with four or more children to 11 percent for those with only one child.

Facility characteristics appear to play an important role in a woman's decision to continue with the same facility or to switch. The highest percentage of switching was observed among women who had attended NGO facilities. With regard to the type of facility, least switching was observed among women who sought services from health centres.

\section{Table 7: Percentage of women, who switched facilities for antenatal care, by selected characteristics}

\begin{tabular}{|c|l|l|l|}
\hline Characteristics & Percentage & $\begin{array}{l}\text { Number of } \\
\text { Women }\end{array}$ & p-value \\
\hline Age & & & \\
$15-19$ & 10.4 & 173 & 1201 \\
$20-29$ & $9.7)$ & 408 & \\
$30-46$ & 6.1 & & 0.074 \\
\hline Marital Status & & 1606 & \\
Single & 8.7 & 192 & 0.416 \\
\hline Educational Level & 10.4 & & \\
None or Primary & & 1098 & \\
Secondary or more & 7.1 & 694 & 0.001 \\
\hline Number of living children & 11.7 & & \\
2 & 10.7 & 701 & \\
3 & 9.2 & 445 & \\
$4+$ & 9.5 & 252 & 0.007 \\
\hline Sector of Facility First Visited & 4.6 & 395 & \\
Govt & 8.5 & & \\
NGO & 12.6 & 873 & \\
NCC & 6.7 & 397 & \\
Dispensary & 10.5 & 525 & \\
Health Centre & 6.5 & 266 & \\
Hospital & 11.0 & 851 & \\
\hline Type of Facility First Visited & 683 & \\
\hline
\end{tabular}

When antenatal women switched to a second health facility, they tended to maintain their loyalty to the sector of the original facility visited. This is demonstrated in Table 6 which shows that the largest proportions of clients who switched facilities continued to seek care within facilities in the same sector. However, for clients who had started with NCC facilities, the choice of which facilities to move to did not appear to be clear. Though the largest proportion of them (37 percent) continued within NCC facilities, there was an even percentage distribution between the other two sectors (NGO and Government). 
Table 8: Antenatal switching, by sector of health facility

\begin{tabular}{|l|l|l|l|l|l|}
\hline \multirow{2}{*}{ Sector first visited } & \multicolumn{4}{|c|}{ Sector Used After Switching } & Number \\
\hline & Government & NGO & NCC & Total (\%) & \\
\hline Government & 55.9 & 25.8 & 18.3 & 100 & 93 \\
\hline NGO & 36.0 & 52.0 & 12.0 & 100 & 25 \\
\hline NCC & 31.7 & 31.7 & 36.6 & 100 & 41 \\
\hline
\end{tabular}

Although women were generally loyal to the sectors of their choice of original health facilities visited, this was found not to be the case with regard to the type. Switching was more prevalent among women who initially visited dispensaries and hospitals than among those who sought care from health centres. However, Table 9 shows that, among women who switched initially from dispensaries, the vast majority of them went on to seek care from hospitals (71 percent). Though the figures are not as pronounced for women who started with health centres and hospitals, it is clear that hospitals tended to attract the largest or second largest proportion of switchers.

\section{Table 9: Antenatal switching, by type of health facility}

\begin{tabular}{|c|c|c|c|c|c|}
\hline \multirow{2}{*}{$\begin{array}{l}\text { Type of facility } \\
\text { switched from }\end{array}$} & \multicolumn{4}{|c|}{ Facility Type Used After Switching } & \multirow{2}{*}{ Number } \\
\hline & Dispensary & Health Center & Hospital & Total (\%) & \\
\hline Dispensary & 14.7 & 14.7 & 70.6 & 100 & 34 \\
\hline Health Centre & 18.1 & 38.9 & 43.1 & 100 & 72 \\
\hline Hospital & 18.9 & 41.5 & 39.6 & 100 & 53 \\
\hline
\end{tabular}

The pattern of switching among antenatal women tended to be towards bigger types of facilities; health centres and hospitals, and this strongly suggests that they were attracted to what they perceived to be higher levels of service quality as the time of delivery was approaching. This explanation is plausible because the highest percentage of switching was to hospitals followed by health centres. Though women can deliver at dispensaries, these facilities are generally ill - equipped in terms of staff, equipment and supplies to handle complicated cases of pregnancy. In Kenya, women tend to register initially with dispensaries for antenatal care, but as the pregnancy approaches term, they switch to facilities that offer higher levels of care. This tendency seems to be confirmed by the relatively low levels of switching for clients who initially sought care at hospitals and health centres.

The potential effect of two personal characteristics, education and number of living children, on switching behaviour is interesting. Educated women were more likely to be discriminating in terms of service quality and hence more likely to seek alternatives in the event of dissatisfaction. That women with higher parity were less likely to switch health facilities probably reflects the considered choice and experience of this group of women. These mothers were likely to know which facilities were better equipped, with skilled service providers and hence their first choice was well considered. However, when the number of children is considered as an explanatory variable together with other variables, the effect of education is dominant. 


\subsection{Switching Facilities for the Same Service: Child Welfare}

An analysis similar to the one conducted for antenatal clients is performed in this section. As was the case with antenatal services, only a small percentage (13 percent) of women changed facilities while seeking health services for the same child.

Switching facilities while seeking child health services was influenced by four personal characteristics (age, marital status, education, number of living children) and the type of the facility visited the first time. Table 10 shows that women in the age group 20-29 years had the greatest likelihood of switching. Single women were more likely to switch facilities compared to those who were married. Women with fewer children were more likely to switch health facilities. The percentage of women who switched decreases steadily from 15 percent for women with one or two children to eight percent for those with four or more. Higher levels of education appear to be associated with higher chances of switching, that is, a higher proportion of women with secondary education switched facilities than their counterparts with primary or no education.

\section{Table 10: Clients Who Switched Facilities For Child Health Services By Selected Characteristics}

\begin{tabular}{|c|l|l|l|}
\hline Characteristics & $\begin{array}{l}\text { Percent Who Switched } \\
\text { facilities }\end{array}$ & Number of women & p-value \\
\hline Age & 7.3 & 179 & \\
$15-19$ & 15.5 & 212 & \\
$20-29$ & 9.2 & 415 & 0.000 \\
$30-46$ & 12.6 & & \\
Marital Status & 17.6 & 1623 & 0.047 \\
Married & 11.6 & 199 & \\
Single & 15.6 & 1116 & 0.016 \\
\hline Educational Level & & 700 & \\
None or Primary & 15.3 & & \\
Secondary or more & 15.0 & 712 & \\
Number of living children & 11.4 & 452 & 0.003 \\
2 & 8.0 & 254 & \\
3 & 14.1 & 399 & \\
$4+$ & 12.5 & 849 & \\
\hline Sector Switched From & 351 & \\
Government & 12.1 & 595 & \\
NGO & 25.5 & 595 & \\
NCC & 12.6 & 937 & \\
\hline Type Switched From & 8.2 & 587 & \\
Dispensary & & \\
Health Centre & & \\
Hospital & & \\
\hline
\end{tabular}

Once women had decided to switch to a second facility, the pattern of the type and sector of these facilities is clear (Table 11 and 12). Regardless of the first health facility used, the largest proportion

of women moved to health centres. Again, the largest proportion of women switched to health 
centres. Kenyan health centres tend to be better stocked with drugs and vaccines compared to dispensaries. At times, the stock situation at health centres is better than at hospitals. Again, this suggests that women were switching in search of facilities that they perceived to offer better quality.

The move to Government or NCC facilities was likely to be associated with the low cost of services. The cost of service for children under five years are nearly free for clients who visit Government health facilities and this may attract a large segment of clients. A qualitative study of participants in focus group discussions and in-depth interviews echoed the favoured position of public facilities because of low cost (Ndhlovu et al., 1995)

\section{Table 11: Switching for child health services, by type of health facility}

\begin{tabular}{|l|c|c|c|c|c|}
\hline $\begin{array}{l}\text { Type of Facility } \\
\text { First Visited }\end{array}$ & \multicolumn{3}{|c|}{ Type of Facility Used After Switching } & $\begin{array}{c}\text { Total } \\
\text { (\%) }\end{array}$ & $\begin{array}{c}\text { Total No. of } \\
\text { Cases }\end{array}$ \\
\hline & Dispensary & $\begin{array}{c}\text { Health } \\
\text { Centre }\end{array}$ & Hospital & \\
\hline Dispensary & 25.3 & 49.3 & 25.3 & 100 & 75 \\
\hline Health Centre & 25.6 & 60.5 & 14.0 & 100 & 86 \\
\hline Hospital & 24.0 & 42.7 & 33.3 & 100 & 75 \\
\hline Column Total & 59 & 121 & 56 & 100 & 236 \\
\hline
\end{tabular}

Table 12: Switching for child health services, by sector of health facility

\begin{tabular}{|l|c|c|c|c|c|}
\hline $\begin{array}{l}\text { Sector First } \\
\text { Visited }\end{array}$ & \multicolumn{3}{|c|}{ Sector Used After Switching } & $\begin{array}{c}\text { Total } \\
\text { percent }\end{array}$ & $\begin{array}{c}\text { Total No. of } \\
\text { Cases }\end{array}$ \\
\hline & Government & NGO & NCC & & \\
\hline Government & 52.9 & 16.8 & 30.3 & 100 & 119 \\
\hline NGO & 40.3 & 35.5 & 24.2 & 100 & 62 \\
\hline NCC & 41.8 & 16.4 & 41.8 & 100 & 55 \\
\hline
\end{tabular}

These results were adjusted for confounding effects of each of the variables on each other by applying multivariate logistic regression techniques. Women aged 20 to 29 years still appear to have a high likelihood of switching. In addition, when other variables are adjusted for the sector and type of facility, there are minimal changes in the likelihood of switching associated with more children, particularly for women who had four or more children. The multivariate analysis further confirms observations from the bivariate analysis that least switching occurred among women who started childcare at health centres or hospitals. 
Women's personal characteristics associated with switching behaviour were found to be different for antenatal and child welfare clients. Clearly, education had a strong effect on switching behaviour for antenatal clients and rather a weak effect among clients seeking child health services. Overall, with higher education, women were more likely to switch to other facilities. Age had a particularly strong influence among mothers seeking health for their children but was of little consequence for antenatal women. However, for both antenatal and child welfare women, there appeared to be an increasing likelihood to switch associated with fewer children, but the effect is significant only among child welfare clients.

Based on reasons given by clients and patterns of switching between the types and sectors of facilities, there is a strong suggestion that cost and quality of services may account for women's motivation to switch. Health centres appeared to be the dominant choice of type of facility switched to. Contrary to expectations, the reasons for switching as given by clients did not feature "better services". Among antenatal clients who switched, 32 percent of them mentioned "better quality" as the reason for changing the facility. The rest identified cost, distance and change of residence as reasons. For child welfare clients, only 12 percent mentioned quality related reasons. The switch to government facilities while seeking child health services suggests that cost considerations were important. Women may take advantage of the relatively free services offered for children under five years of age.

\subsection{Switching Facilities between Services: ANC to Child Health}

The integration of $\mathrm{MCH}$ services in Kenya allows women to continue seeking childcare from the same facility where they deliver their babies. The previous sections have demonstrated that switching facilities for the same service, that is, antenatal or child health was relatively low, respectively nine and 13 percent. However, data show that a far higher percentage of women switched facilities when their needs changed from antenatal care to child care. Nearly a quarter (23 percent) of them reported that they switched facilities after delivery. This group of women forms the basis for analysis of this section.

Table 13 shows the bivariate analysis of personal and facility characteristics for women who switched facilities. Apart from the number of children and the age of the woman, all other personal characteristics do not show a significant association with switching behaviour. Though the effect of parity is demonstrated to be strong, that of age is weak and diminishes once all the variables are adjusted for each other in the multivariate logistic regression model. The inverse relationship between parity and the chances of switching is noted and the pattern continues even after adjustment.

The important role played by the type and sector of facility visited by women for antenatal care was explored by applying the multivariate logistic regression models. Results show that women who sought antenatal care from NGO facilities were more than twice as likely to switch facilities than those who had sought antenatal care from the Government sector. This strongly contrasts with very low switching noted among clients who sought care from NCC facilities. Compared to dispensaries, 
data show that there was a decreasing likelihood to switch for women who visited health centres and hospitals

\section{Table 13: Characteristics of women who switched facilities when they changed services from antenatal care to child welfare}

\begin{tabular}{|c|l|l|l|}
\hline Characteristics & Percentage & Number of women & p-value \\
\hline Age & & & \\
$15-19$ & 28.8 & 177 & \\
$20-29$ & 23.7 & 1201 & \\
$30-46$ & 20.3 & 413 & 0.077 \\
\hline Marital Status & 22.6 & 1610 & \\
Married & 28.4 & 197 & 0.068 \\
Single & & & \\
Educational Level & 22.1 & 1108 & \\
None or Primary & 24.9 & 655 & \\
Secondary or more & & & \\
Number of living children & 26.5 & 706 & \\
1 & 24.3 & 448 & \\
2 & 22.4 & 254 & 0.001 \\
3 & 16.2 & 394 & \\
$4+$ & & & \\
Sector Switched From & 20.8 & 859 & 0.000 \\
Government & 35.1 & 396 & \\
NGO & 13.6 & 520 & \\
NCC & & & \\
Type Switched From & 40.9 & 835 & 0.000 \\
Dispensary & 15.8 & 679 & \\
Health Centre & 22.1 & & \\
Hospital & & & \\
\hline
\end{tabular}

Tables 14 and 15 shows the sector and type of facilities that women chose to visit once they decided to switch. Loyalty to the sector of the facility first visited continued even after switching. In particular, this was the case for women who visited Government and NCC facilities where 51 and 73 percent of switchers, respectively remained within the same sector. Though a similar pattern occurred for the NGO sector, a more even spread of switchers to other sectors is depicted. With respect to the type of facility switched to, the largest proportion of women changed to health centres. 


\section{Table 14: Switching from antenatal services to child health services, by sector of health facility}

\begin{tabular}{|l|l|l|l|l|l|}
\hline \multirow{2}{*}{$\begin{array}{l}\text { Sector first visited for } \\
\text { ANC }\end{array}$} & \multicolumn{3}{|c|}{ Sector Used After Switching for child health } & \multirow{2}{*}{ Number } \\
\cline { 2 - 5 } & Government & NGO & NCC & Total (\%) & \\
\hline Government & 51.4 & 29.4 & 19.2 & 100 & 177 \\
NGO & 40.3 & 30.9 & 28.8 & 100 & 139 \\
NCC & 16.9 & 9.8 & 73.2 & 100 & 71 \\
\hline
\end{tabular}

\section{Table 15: Switching from antenatal services to child health services, by type of health facility}

\begin{tabular}{|l|l|l|l|l|l|}
\hline $\begin{array}{l}\text { Type of facility used } \\
\text { during antenatal care }\end{array}$ & \multicolumn{3}{|c|}{ Type of facility Used After Switching } & Number \\
& Dispensary & Health centre & Hospital & Total (\%) & \\
Dispensary & 27.8 & 45.4 & 26.8 & 100 & 108 \\
Health Centre & 19.8 & 67.9 & 12.2 & 100 & 131 \\
Hospital & 33.3 & 40.0 & 26.7 & 100 & 150 \\
\hline
\end{tabular}

Findings from this section strongly suggest that the cost of services and quality offered at health facilities strongly motivate the choice of facilities for the majority of women. In this case, the only personal characteristic that appeared to be related to switching behaviour was parity. It appears that parity in this case could be taken as a proxy for experience. Women with more children are likely to be familiar with the quality of services offered and consequently know where to go for the different services.

The general choice of government facilities for switchers strongly suggests that cost of services was a key factor for the choice. Government and NCC facilities tend to be well stocked with vaccines for children and they are almost free for clients. Other services such as weighing children and routine baby checks are also available at these facilities. Once these services are available, there is little variation in terms of quality considerations. On the other hand, NGO facilities charge for these services and this may account for the high probability of switching associated with NGO facilities.

\subsection{Switching Facilities between Services: Child Health to FP}

Of the 1834 women who were interviewed, 49 percent had used family planning since the birth of their last child. The majority (79 percent) of this group used the same facility for family planning as they had used for antenatal or child welfare services. Once these women started using family planning services, 86 percent of them continued to use the same facility. Since the main interest in this section is use of modern contraceptives, only those women who had ever used contraceptives form the sample for analysis. The first part of the analysis examines the factors that could influence women's decision to seek family planning services elsewhere even though these services were available at the facilities that they previously visited for other purposes. The second part of the 
discussion is based on a group of 117 women who reported that they had switched from one facility to another for family planning purposes.

In addition to personal and facility characteristics used in the previous sections, family planning exposure variables will be considered as potential explanatory variables for analysing switching behaviour. The key variables for family planning exposure are: whether providers counselled clients about family planning; whether clients discussed family planning services with other women; and if they had seen posters at the facilities visited.

Table 16 shows the percentage of women who switched facilities for family planning services with respect to selected characteristics. Women exposed to family planning information during child health were less likely to switch than those who were not. Though the results are of marginal statistical significance, women who reported that they had seen posters during their child welfare visits were also less likely to switch health facilities. Additionally, a friendly environment of services appeared to promote use of the same facilities for both family planning and child health. A smaller percentage of women switched when they were able to discuss family planning services with other women. This could also mean that women continued seeking services at facilities where they had friends. 


\section{Table 16: Percentage of women who used different facilities for child welfare and family planning services since last birth by selected characteristics}

\begin{tabular}{|c|c|c|c|}
\hline Factor & $\begin{array}{l}\text { Percentage } \\
\text { switched }\end{array}$ & Number of women & p-value \\
\hline \multicolumn{4}{|l|}{ Age } \\
\hline $15-19$ & 15.2 & 46 & \\
\hline $20-29$ & 22.4 & 598 & \\
\hline $30-46$ & 18.3 & 252 & 0.247 \\
\hline \multicolumn{4}{|l|}{ Marital Status } \\
\hline Married & 19.9 & 833 & \\
\hline Single & 33.3 & 66 & 0.010 \\
\hline \multicolumn{4}{|c|}{ Number of living children } \\
\hline 1 & 22.8 & 316 & \\
\hline 2 & 23.1 & 242 & \\
\hline 3 & 15.9 & 138 & \\
\hline $4+$ & 18.1 & 204 & 0.219 \\
\hline \multicolumn{4}{|l|}{ FP Exposure Variables } \\
\hline \multicolumn{4}{|c|}{$\begin{array}{l}\text { Provider Discussed FP during CW } \\
\text { visits }\end{array}$} \\
\hline Yes & 18.3 & 622 & \\
\hline No & 26.8 & 280 & 0.003 \\
\hline \multicolumn{4}{|l|}{ Client Saw Posters } \\
\hline Yes & 19.7 & 766 & \\
\hline No & 27.2 & 136 & 0.047 \\
\hline \multicolumn{4}{|c|}{$\begin{array}{l}\text { Client Discussed FP with other } \\
\text { women }\end{array}$} \\
\hline Yes & 17.2 & 547 & \\
\hline No & 26.5 & 355 & 0.001 \\
\hline \multicolumn{4}{|c|}{ Last Facility Type During CW visits } \\
\hline Dispensary & 27.7 & 146 & \\
\hline Health Centre & 18.4 & 473 & \\
\hline Hospital & 21.5 & 270 & 0.049 \\
\hline \multicolumn{4}{|c|}{ Last Facility Type during $\mathrm{CW}$ visits } \\
\hline Government & 19.4 & 396 & \\
\hline NGO & 28.9 & 166 & \\
\hline NCC & 17.8 & 326 & 0.011 \\
\hline
\end{tabular}

We also note from Table 16 that the type of sector used during child health care was more strongly associated with switching than the type of facility. Switching was most common among women who attended dispensaries during child welfare visits. Clients who had visited health centres and hospitals were least likely to switch facilities. With regard to type, women who attended NGO facilities for child welfare were also more prone to switch facilities. For instance, logistic regression analysis shows that these women had a probability of switching one and half times more than those attending Government health facilities. NCC clients tended to remain within the same sector. 


\subsection{Switching Facilities for the Same Service: Family Planning}

The small group of 117 women who used at least two facilities for family planning services are investigated further to see the factors associated with their switching behaviour. The age range for these women was 17 to 43 years, with mean and median of 27 and 26 years respectively. Just over three-quarters of them were married and 48 percent with primary education. With regard to children, the mean number was found to be two and approximately 41 percent of these women still wanted to have more children while over half stated that they wanted to terminate child birth.

When women's personal characteristics were analysed for association with switching for family planning services, only marital status showed a strong association while age was of marginal significance (Table 17). From the table we see that the percentage of single women who switched was more than two times that of married women. With regard to age, women aged 30 years and above were more likely to switch facilities than those in the 15 to 19 or 20 to 29 year age brackets.

\section{Table 17: Comparison of selected characteristics for women who switched FP sources and those who did not since the birth of the last child.}

\begin{tabular}{|c|c|c|c|}
\hline Selected Characteristics & Switchers & Number of women & p-value \\
\hline \multicolumn{4}{|l|}{ Age } \\
\hline $15-19$ & 11.1 & 45 & \multirow[b]{3}{*}{0.051} \\
\hline $20-29$ & 11.4 & 595 & \\
\hline $30-46$ & 17.5 & 251 & \\
\hline \multicolumn{4}{|l|}{ Marital Status } \\
\hline Married & 11.9 & 830 & \multirow[b]{2}{*}{0.000} \\
\hline Single & 27.3 & 66 & \\
\hline \multicolumn{4}{|l|}{ Number of living children } \\
\hline 1 & 13.0 & 313 & \multirow[b]{4}{*}{0.286} \\
\hline 2 & 14.3 & 241 & \\
\hline 3 & 15.9 & 138 & \\
\hline $4+$ & 9.3 & 204 & \\
\hline \multicolumn{4}{|c|}{$\begin{array}{l}\text { Person Recommending First } \\
\text { Method }\end{array}$} \\
\hline Providers & 15.1 & 317 & \multirow[b]{3}{*}{0.000} \\
\hline Friends & 25.6 & 86 & \\
\hline Self & 9.5 & 495 & \\
\hline \multicolumn{4}{|l|}{ Method First Used } \\
\hline Pill & 15.2 & 514 & \\
\hline IUD & 20.0 & 40 & \\
\hline Depo Provera & 9.7 & 299 & 0.041 \\
\hline
\end{tabular}


The multivariate logistic regression analysis confirms the influence of the two personal characteristics on women's switching behaviour. Marital status shows a strong effect on switching behaviour; single women were found to be nearly three times as likely to switch facilities than married women. In fact, the effect increases after adjusting for other explanatory variables shown in the same table. Age, which was of marginal significance for unadjusted odds ratios, loses its importance when considered with other variables.

The first method adopted by women after delivery is closely associated with switching of health facilities. Over half of these women (57 percent) reported that they had started contraceptive use with the pill. Depo provera ranked second with a third of women reporting its use while the IUD was used by only 4 percent. Condoms and other methods were not popular at all; each used by less than five percent of women. Most switching was associated with use of the IUD with 20 percent reporting switching clinics. The pill which was associated with switching of about 15 percent ranked second. Least switching was observed among women who had adopted depo provera as a contraceptive method. The multivariate and bivariate analysis were found to be in conformity.

There is a strong suggestion that contraceptive choice and side effects were key considerations for switching facilities for family planning services. Of the 117 women who used at least two health facilities for family planning, 33 percent of them reported that they also changed methods. Twentyseven of these switchers started use with the pill and the majority of them switched to depo provera; eight who were on depo provera switched to the pill and two who had started with the IUD switched to the pill.

This last part of the report showed the role played by service providers and friends in choosing the first contraceptive after delivery. Data show that switching behaviour was highly influenced by the person mainly responsible for recommending the method used postpartum. The largest percentage of women (55 percent) reported that they used the contraceptive method out of personal choice while 35 percent cited providers and 10 percent friends and relatives. When switching was analysed with respect to the person who recommended the method, it was found that the largest group of switchers was among women who reported that friends were instrumental in choice of method (26 percent) followed by those who cited providers (15 percent). Table 6.20, shows that women who adopted a method recommended by a friend were nearly twice as likely to switch than when a provider recommended the method. Least switching was noted among women who said they had used a contraceptive that they themselves had chosen ( 9 percent). This finding highlights the importance of individual choice in contraceptive use.

Switchers were asked indirect questions of what they thought accounted for women's decisions to discontinue health facilities and seek services elsewhere. Though most responses attributed discontinuation to distance of service facilities, issues of service quality also featured prominently. For example, 73 percent of these women spontaneously mentioned access (distance and cost) and the rest of the reasons were related to the quality of services: unavailability of methods (7 percent), lack of water and supplies and provider unhelpfulness with side effects. 


\section{Discussion and Conclusions}

Results from the study highlighted a number of findings which may be key in organising MCH and family planning programmes. The majority of women in Kenya tended to use the same health facilities for each of the three services of antenatal care, child health and family planning. This situation offers a great opportunity for service providers to inform and educate women on a number of health issues. A percentage of women who switched facilities for the same service were of particular interest to the investigation. These women provided insights into patterns of switching behaviour and the role of service quality in the choice of the health facilities.

The Government policy requiring that service providers should expose clients to family planning information during antenatal and child welfare is evidently leading to a lack of a coherent strategy ${ }^{1}$. As a result, some women with unmet need for family planning services leave facilities without receiving information about these services. Use of health talks for general health education combined with more focused procedures for identifying clients with unmet need can be adopted during provider-client interactions. In-service training programmes should device focused ways of training service providers how to identify MCH clients with unmet need for family planning services.

The high likelihood that women who were exposed to family planning in general and provider counselling in particular were more likely to initiate contraceptive use is encouraging for programmes. Though a direct causal link cannot be established between family planning exposure and contraceptive uptake, the finding supports the rationale for IEC activities at health facilities. Counselling women about family planning during their visits for antenatal care and child health appears to be a viable strategy of providing them with health information and a wider range of reproductive health issues (for example, sexually transmitted diseases), can be considered for incorporation.

Clients' personal characteristics appear to play a critical role in their switching behaviour and those selected for counselling by service providers. Based on these criteria, providers make sensible decisions who to counsel for family planning services. At the same time, these considerations lead to restrictions of access to contraceptive information for some groups of women who may be in need of services. In particular, young women appeared to bear the burden of these attitudes. The government should continue to explore ways of reducing medical barriers to family planning service provision and to providing services to young unmarried adults.

Switching behaviour was also found to be influenced by clients' individual characteristics though these were not consistent for all the three services of antenatal care, child health and family planning. The effects of age, parity and marital status were most significant in switching of facilities for same services for child welfare and family planning. Similar effects were also noted in switching between services; antenatal care to child welfare and child welfare to family planning. The likelihood of

\footnotetext{
${ }^{1}$ The Government Population Guidelines states that "The Ministry would expand its ability to incorporate population related information at all the service delivery points, mobile units and the primary health care projects to cater for more adolescent and men". In the National Implementation Plan, the Government identified women with unmet need as a focus audience.
} 
switching associated with these factors could be a reflection of changes in women's life course events, particularly occasioned by marriage and employment. The influence of education was most pronounced in all instances of switching, although most significant for antenatal care. This is not very surprising because the gains derived from female education are well documented in reproductive health literature. More educated women are better informed because they are able to gather information from various sources and are usually more articulate in their choice of services.

The high switching behaviour observed among single women seeking family planning services strongly suggests that the family planning programme is not catering for their needs. This finding corroborates the experiences of single women who acted as mystery clients during the qualitative study conducted in 1995 (Ndhlovu, 1995) and documentation from other studies (Hughes et al., 1998).

Women who discussed family planning services with other women during child health visits were more likely to continue using the same facility. Continuity with the same facility for clients exposed to this mode of information is relevant for $\mathrm{MCH}$ and family planning programmes. The use of peer counsellors is strongly suggested by the low level of switching among clients who discussed with other women.

The importance of involving family planning clients in adequate method counselling is supported by the finding that women who chose the contraceptives to use were least likely to switch facilities. Where contraindications to the preferred method are identified, providers have to counsel women sufficiently.

The net effects of the type and sector of facility in the exposure of clients to family planning information and switching of facilities were particularly evident. Similar results were observed in switching between services for antenatal to child welfare and child welfare to family planning. Most reasons for switching appear to be related to service quality and cost. Government and NCC facilities generally offer cheaper services and that may explain why switching tends towards these sectors. With regard to city council facilities, extensive interventions in provider training and upgrading the infrastructure prior to the survey, could account for a switch to these facilities. Throughout the discussion, there is strong evidence that clients who visited health facilities run by these institutions were more likely to be counselled in family planning services. The government of Kenya can draw lessons from the quality of services delivered to clients by the Nairobi City Council and the NGO sector.

If the call by the ICPD for integrating services (especially sexually transmitted infections) as part of service quality is to be heeded, considerable work remains to be done at national and health facility levels before its goals can be realised. However, this study showed that there is a potential role of improving service quality by including information given to clients during their visits for antenatal and child health services. At the same time, the tendency for clients to switch to hospitals and dispensaries strongly suggests that quality is an important factor in women's choice of services. 
The original design of the research sought to investigate two links between clients and services at health facilities, the conversion and attraction links. The attraction link proposes that clients are more attracted to health facilities where the quality of services is better in terms of the infrastructure and interpersonal relations. On the other hand, the conversion link proposes that at facilities where service providers actively engage in providing family planning information during antenatal and child health visits, a higher uptake of contraceptive use and continuation can be experienced. Results from this research largely support the two links.

The pattern of switching of health facilities for different services provides support for the attraction link of hypothesis. Along with cost and distance to facilities, clients tended to switch to higher levels of facilities and this suggested that they were seeking for better functioning facilities with bettertrained providers. The general tendency of women to switch from the Government and NGO sectors to the Nairobi city council facilities supports these assertions. Prior to the survey, the Nairobi City Council facilities received extensive support in terms of refurbishing the infrastructure and training of service providers. This improvement in quality appears to have been responsible for the attraction of its services.

Though less data was available for examining the conversion link, evidence supports this link. The study showed that women who were exposed to family planning information when they sought antenatal care were about twice as likely to initiate contraceptive use after birth. In addition, women who were exposed to family planning information during child health visits to facilities continued to use the same facility. In light of these results, reproductive health programmes are encouraged to strive for higher quality both in $\mathrm{MCH}$ and family planning services. Integration of information at different levels of care has wide potential benefits and there is scope for providing more information to clients. 


\section{Reference:}

Bruce, J “ Fundamental Elements of the Quality of Care: A Simple Framework.” Studied in Family Planning 1990; 21(2):61-91.

Chayovan, Napaporn, Albert I. Hermalin, and John Knodel. 1984. "Measuring Accessibility to Family Planning Services in Rural Thailand. "Studies in Family Planning 15 (5): 201-211.

Cochrane, Susan and Laura Gibney. July, 1991."Does Better Access to Contraceptive Increase their Use? Key Methodological Issues" July 1991. World Bank Working Papers.

Cotten, Niki, John Stanback, Halima Maidouka, Joseph T. Taylor-Thomas and Tom Turk (1992) "Early Discontinuation of Contraceptive Use in Niger and The Gambia" International Family Planning Perspectives, Vol. 18, 4: 145-149.

Fisher, A (1993) "Family Planning in Africa: Summary of Recent Results from Operations Research Studies" in "Africa Operations Research and Technical Assistance Project: End of Project Conference, 4-7 October, 1993. The Population Council, Nairobi Hilton, Kenya.

Hughes, Jane and Ann P. McCauley (1998) “Improving the Fit: Adolescents' Needs and Future Programs for Sexual and Reproductive Health in Developing Countries" Studies in Family Planning, 29:2:233-244.

Jain, A. (1989) "Fertility Reduction and the Quality of Family Planning Services" Studies in Family Planning. 20: $1-16$.

Koenig, M.A, M Whittaker (1997) "The influence of quality of care upon contraceptive uptake in rural Bangladesh." Studies in Family Planning; 28 (40:278-289).

Mench, Barbara, Andrew Fisher, Ian Askew, and Ayorinde Ajayi (1994) " Using Situation Analysis Data to Assess the Functioning of Family Planning Clinics in Nigeria, Tanzania and Zimbabwe." Studies in Family Planning_25,1:1-17.

Miller, Kate, Robert Miller, Goli Fassihian and Heidi Jones (1998) “How Providers Restrict Access to Family Planning Methods: Results from Five African Countries" in Clinic Based Family Planning and Reproductive health Services in Africa: Findings form Situation Analysis Studies, ed. Kate Miller, Robert Miller, Ian Askew, Marjorie Horn and Lewis Ndhlovu. Population Council and US Agency for International Development.

National Council for Population and Development (1989). Kenya Demographic Health Survey Report 1994. Nairobi. National Council for Population and Development., Central Bureau of Statistics and Macro international Inc.

Ndhlovu, L, J. Solo, R. Miller and A. Omondo (1996) “ An Assessment of Clinic based Family Planning Services in Kenya: Results form the 1995 Situation Analysis." Ministry of Health, Division of Family Health, Nairobi, Kenya, and The Population Council, New York.

Ndhlovu, Lewis "Quality of Care in Family Planning Service Delivery in Kenya: Clients' and Providers Perspectives" The Population Council, 1995. Nairobi.

Pariani, Siti, David M.Heer, and Maurice D. Van Arsdol, Jr. (1991) "Does Choice Make a Difference to Contraceptive Use? Evidence from East Java” Studies in Family Planning; 1991;22(6)384-390.

Wilkinson, Marilyn I., Wamucii Njogu, and Noureddine Abderrahim (1993). The Availability of Family Planning and Maternal and Child Health Services. DHS Comparative Studies No. 7. Columbia, Maryland: Macro International Inc. 